\title{
Field Experiments and Technical Evaluation of an Optimized Media Evaporative Cooler for Gas Turbine Power Augmentation
}

\author{
A. Behdashti ${ }^{1}$, M. Ebrahimpour ${ }^{2}$, B. Vahidi $^{* 2}$, V.Omidipour $^{1}$, A.Alizadeh $^{3}$ \\ ${ }^{1}$ E-Man Serve co, \\ Alvand Tower, Alikhani Boulevard, South Shiraz Ave, \\ Tehran 1436944961, Iran. \\ ${ }^{2}$ Department of Electrical Engineering, \\ Amirkabir University of Technology, \\ Hafez Ave, Tehran 1591634311, Iran. \\ *vahidi@aut.ac.ir \\ ${ }^{3}$ Kerman Power Generation co, \\ Abbaspour Boulevard, Kerman 7614651187, Iran.
}

\begin{abstract}
This paper discusses an optimized media type evaporative cooling system called Outdoor Movable Media cooler which has been recently implemented on two 160 MW, V94.2 gas turbines of Kerman combined cycle power plant, Iran. The air cooling system can be applied to retrieve the lost power generation capability of gas turbine during hot months.

System description is completely presented and optimizations such as making a movable media cooler are described. The moving ability of this system eliminates the power loss related to the conventional media coolers. Furthermore, experimental work including evaluation of humidity effect on the air filters operation is discussed and the results are presented. The cooling system performance curve shows the system capability of cooling the inlet air up to $19^{\circ} \mathrm{C}$ at the design condition. This cooling capacity leads to power augmentation up to $14 \%$ which is noteworthy in responding to the electricity demand in hot months, when air-conditioning loads are maximized. Considering several parameters, a cost analysis is done finally and payback period of the system is calculated.
\end{abstract}

Keywords: Evaporative cooling, gas turbine, media cooler, power augmentation

\section{Introduction}

A gas turbine output power decreases with respect to ISO design condition when ambient temperature rises significantly. A parametric study on the impact of atmospheric conditions on the gas turbine performance is carried out by El-Hadik [1]. The results show reductions of power and efficiency to be about 0.6 and $0.18 \%$, respectively, due to each ${ }^{\circ} \mathrm{C}$ ambient air temperature growth. On the other hand, demand for electric power and the value of electricity are greatest at those times of high ambient air temperature, when airconditioning loads are maximized.

Cooling the inlet air is a common way to retrieve the turbine lost power. It increases mass flow rate of the inlet air, so more work is done by the gas turbine. The cooling technologies can be categorized as the following [2, 3]:
1. Refrigerated systems such as absorption or mechanical chiller

2. Thermal energy storage systems such as ice storage system

3. Evaporative methods including media-type cooler or fog system

A technical review of various inlet air cooling systems is carried out by K. Ibrahim [2]. Several conclusions are drawn including the suitability of evaporative methods in hot and dry climates rather than hot and humid ones. A methodology for economic evaluation of gas turbine inlet cooling systems in combined cycle applications is presented by Gareta [4]. The study shows extreme importance of considering both the climatic and economic frameworks before selecting the type and size of a cooling system. 
B.Omidvar [5] has investigated various inlet cooling techniques including refrigerated systems. These methods can increase turbine output power more than evaporative methods but disadvantages like high initial capital cost, high O\&M cost, long delivery and installation time have made them economically feasible only in hot and humid climates or regions where the water is a major factor.

A summary of an inlet air cooling project for a frame 7EA based combined cycle power plant using a mechanical chiller is presented in [6]. Results show an output increment of $7 \mathrm{MW}$ at design conditions.

Thermoeconomic analysis of an ice thermal energy storage system is performed by S.Sanaye [7], and optimum values of system design parameters are obtained using genetic algorithm optimization technique. This method can utilize low night time tariff to produce and store ice for peak hour operation; i.e., the gas turbine can take advantage of off-peak and mid-peak lower energy cost [8].

Evaporative methods are the most common ways of cooling inlet air because of their simplicity, low installation and O\&M costs, but most effective only for dry-hot climates [9, 10]. Media-based evaporative cooler has been discussed in several studies [11-14]. R.Hosseini [12] modeled a traditional media evaporative cooler installed in a combined cycle power plant, Iran, and evaluated it with different design parameters. Practical aspects of inlet fogging have been described in several papers [15-18]. M.Chaker [18] has studied the influence of fog droplet size on the fogging system evaporation efficiency, results show that the evaporation efficiency increases with a decrease of fog droplet size.

Also novel air cooling methods are presented to enhance gas turbine performance. Utilizing potential cooling capacity of pressure drop in the refinery natural gas pressure drop station to cool the inlet air of gas turbine is investigated by M.Farzaneh [19, 20]. Results show an inlet air temperature reduction of 4 to $25 \mathrm{~K}$ for almost nine months.

Several drawbacks related to traditional media cooler have inspired the solution of replacing it with other cooling systems; specially, the inlet fogging system [3, 21], while optimizing the traditional media cooler as a cost effective cooling system may be a better approach, so in this paper, experimental and technical aspects of an optimized media evaporative cooler are discussed. The description of the system is presented and the ensued advantages are discussed.

\section{Overview of Traditional Media Cooler}

The simple operation of media cooler as a kind of evaporative cooling system has made it an appropriate solution for gas turbine power augmentation. The evaporation surface consists of media pads which are made of fibrous corrugated materials. Water is introduced through a header at the top of the media and is deflected downward on the distribution pads and wets an enormous area of the pads contacted by the passing air. For water evaporation process, the required enthalpy is absorbed from the passing air, causing a decrease in air dry-bulb temperature [22]. Figure 1 illustrates the operation principle of the media evaporative cooling system.

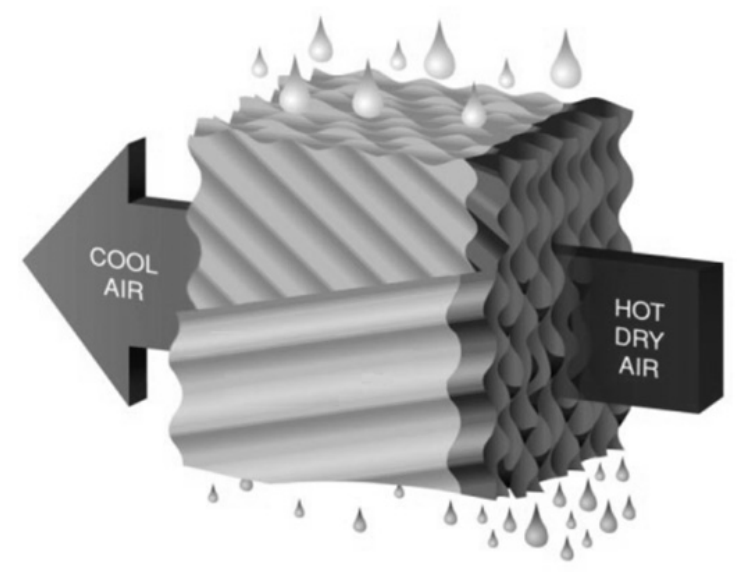

Figure 1. Operation principle of the media evaporative cooling system [23]

Such system is used as a preferred method in dryhot climates, which can be expected to boost gas turbine output power by nearly $12 \%$. Meanwhile, for hot humid climates, the air cooling is limited to the wet bulb temperature and the capacity of gas turbine may not be increased by more than 5 to $7 \%$ in the best cases $[11,23]$. 
Traditional media evaporative coolers have an effectiveness of $85-90 \%$ which means that wet bulb temperature can never be attained [3]. Evaporative cooler effectiveness is given by:

$$
\eta=\frac{T_{D B 1}-T_{D B 2}}{T_{D B 1}-T_{W B}} \times 100
$$

Media pads can be installed downstream or upstream of inlet air filters. Downstream installation has the advantage of preventing dust and other particles from the air to adhere to the media pads, keeping them clean. A mist eliminator is often installed on the downstream side of the media to eliminate water carry-over [12]. Also Downstream installation causes extreme modification of the intake duct which increases the installation time, while upstream installation is free of such modifications. By filtering the inlet air, upstream installation can also postpone the air filters replacement time; i.e., increasing the filters life span. By controlling the amount of sprayed water and a homogenous water distribution in the upstream installation, the water carry-over can be minimized, hence the mist eliminator may be dispensable.

\section{Optimization Work}

The most significant factor affecting the gas turbines' performance is the temperature of the inlet air. However, other factors such as ambient air pressure, which is related to elevation relative to sea level, and pressure drops, associated with the air flow through the inlet duct and filters, would also affect its performance.

Traditional media-type evaporative coolers increase the pressure losses associated with the air flow through the inlet duct resulting in output power loss of about $0.25-0.35 \%$ by each mmWG increase in the inlet duct pressure drop. This is a major drawback as long as the power loss will be experienced by the gas turbine throughout the year, regardless of the evaporative cooling is running or not. This can cost hundreds of thousands of dollars [21].

Making a movable media cooler may be the best idea to eliminate the inherent pressure drop of the traditional evaporative media coolers. To achieve this goal, the Outdoor Movable Media cooler called OMM is designed and experimented on two 160 MW, V94.2 gas turbines of Kerman combined cycle power plant, Iran. The cooler consists of stainless steel doors in which the media pads are inserted. Motor Gearboxes are employed to rotate the doors 90 degrees by means of some axis, hence the pads will be in opened position and no pressure drop would occur when the cooler is not operating. In case of the operation of the cooler, the motor gearboxes turn the doors and put them in closed position. A simple plan schematic of the movable cooler operation is depicted in Figure 2.

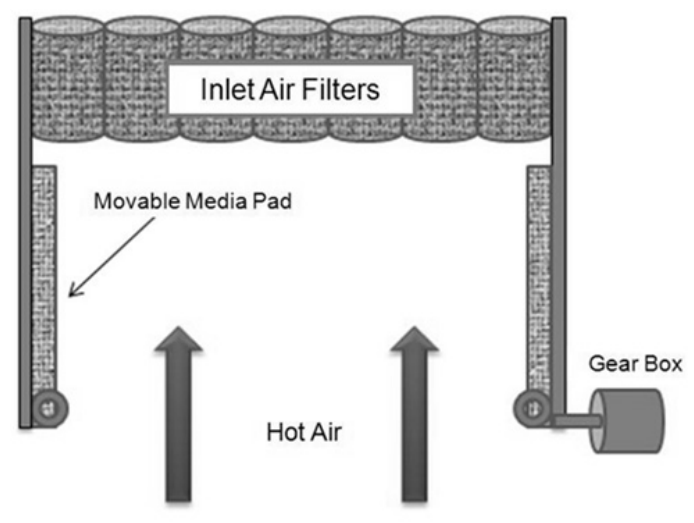

a) Non-operating Mode

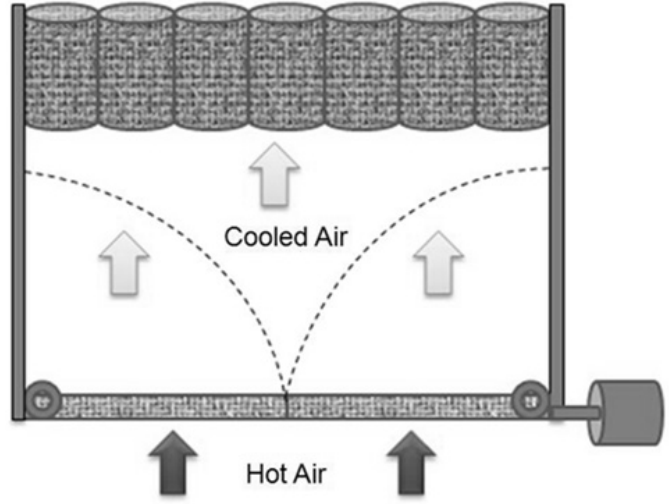

b) Operating Mode

Figure 2. Simple plan schematic of the movable cooler operation 
Outdoor installation is chosen because of the benefits described before, but special attention should be paid to the velocity of the inlet air. High velocity may cause problems such as [12]:

1. Water carry-over phenomenon

2. Decreased cooling efficiency because of incomplete heat transfer between the air and water.

3. Increased inlet pressure drop

The cooler should be designed in such a way not only to avoid the mentioned problems related to the air velocity but also to fulfill the design condition requirements. Design condition of the media cooling system for the Kerman C.C.P.P is $38^{\circ} \mathrm{C}$ temperature and $10 \%$ relative humidity. The installed system should be capable of decreasing the inlet air temperature up to $19^{\circ} \mathrm{C}$ at the design condition [24].

By Equation 1, the cooling efficiency is calculated:

$$
\eta=\frac{38-19}{38-16} \times 100=86.4 \%
$$

Using the saturation efficiency curve given by the manufacturer of the media pads, the air velocity on the pads of $200 \mathrm{~mm}$ thickness, should be about 2.7 $\mathrm{m} / \mathrm{s}$ to achieve the required efficiency, see Figure 3.

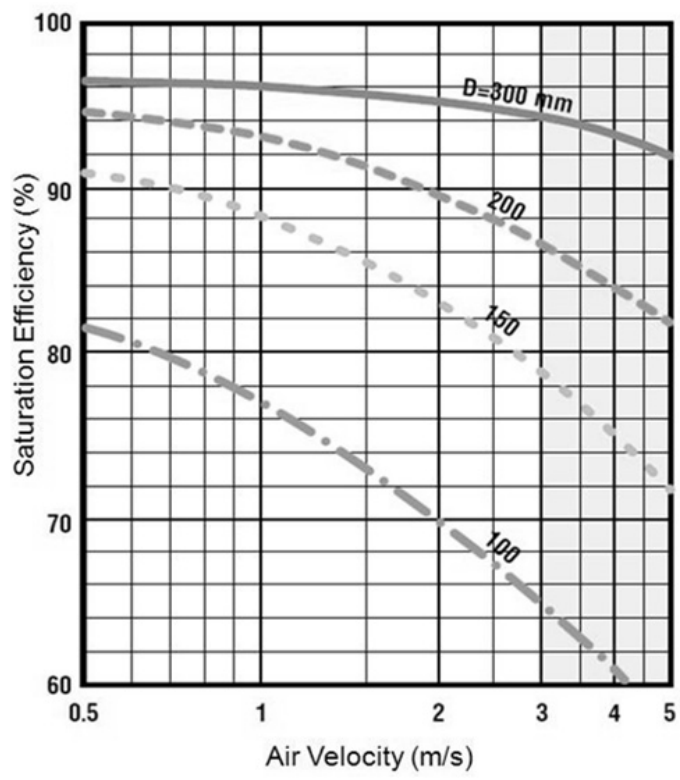

Figure 3. Efficiency versus air velocity of different media pads [25].
The constant air flow rate of V94.2 gas turbine is $428 \mathrm{~m}^{3} / \mathrm{s}$, therefore the required net area of the cooler to ensure the appropriate air velocity will be

$$
A=\frac{428}{2.7} \cong 160 S q m
$$

A cooler with a net area of $160 \mathrm{~m}^{2}$ is designed and a CFD analysis is done to calculate the air velocity on the surface which the media pads will be installed. Result shows a mean value of about 2.7 $\mathrm{m} / \mathrm{s}$ which is appropriate, Figure 4 .

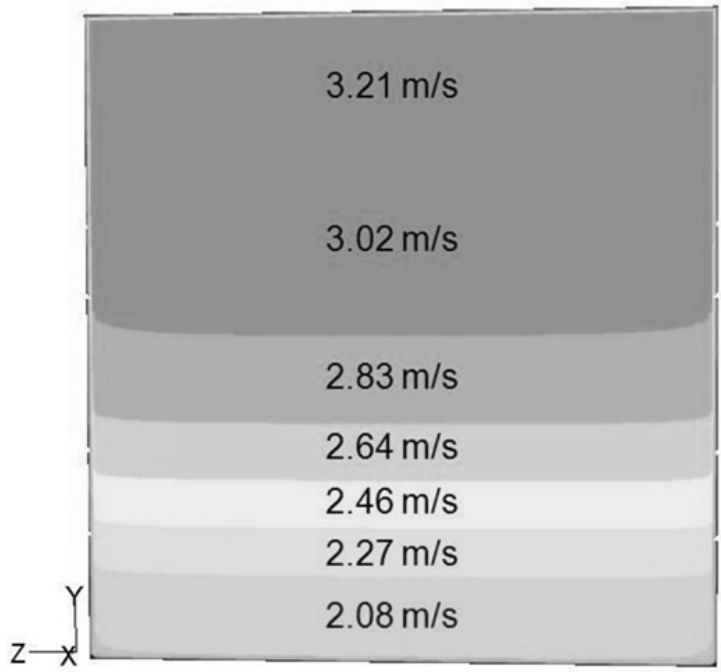

Figure 4. Contours of air velocity magnitude on the surface which the pads are installed.

As shown in Figure 5 and according to the calculations, the cooler box is designed larger than the air intake. Field experimental results confirm the air velocity value calculated by the CFD analysis, hence the air velocity on the media pads is less than $2.8 \mathrm{~m} / \mathrm{s}$ and a negligible water carryover has been reported.

To have a better cooling efficiency, it is needed to equally distribute water over the surface of the media pads, hence the cooler is designed in such a way that not only more water distribution lines have been considered in comparison to traditional coolers, but also water is injected from both sides of the cooler. It will bring a homogenous inlet cooled air, leading to a better cooling efficiency and more output power. 


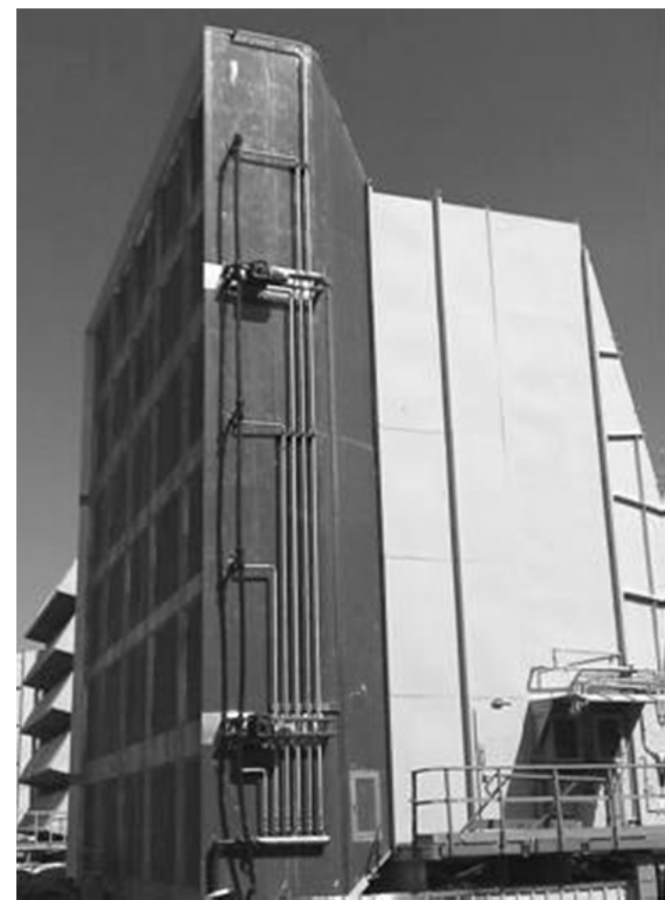

Figure 5. OMM cooler installed on gas turbine unit 3 of Kerman C.C.P.P, Iran.
Water quality requirements for a media cooler is less stringent than those required for Fog cooling system and this is an advantage in locations where demineralized water is expensive or is not easily available[3]. However, water treatment is required in order to deal with problems such as microbiological fouling, corrosion and agglomerations of minerals.

Figure 6 shows a schematic diagram of the experimented OMM cooling system. The makeup water is a kind of soft water with electrical conductivity of less than $350 \mu \mathrm{S}$. At the design condition, approximately $3 / 4$ of the injected water evaporates and $1 / 4$ is recycled and collected in a tank called "sedimentation tank" which has been designed to optimize the water treatment process, in other words, to act as a local pre-treatment unit. In this case, measures such as chemicals dosing to facilitate the sedimentation process in the tank and to prevent microbiological fouling and corrosion on the pads and online water conductivity control are taken.

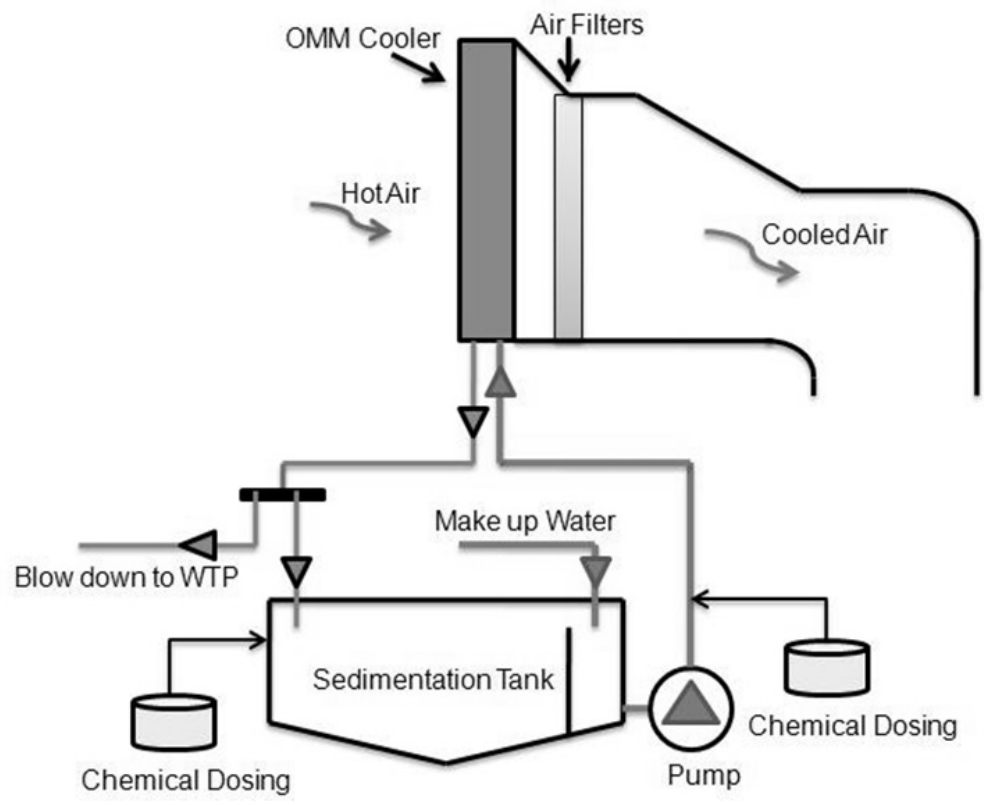

Figure 6. Schematic diagram of the OMM cooling system. 


\section{Results and discussion}

\subsection{Cooling ability and the augmented power}

Based on the collected data, at relative humidity of $12 \%$, the cooling system has decreased the $37^{\circ} \mathrm{C}$ inlet air to $19^{\circ} \mathrm{C}$; i.e., $18^{\circ} \mathrm{C}$ cooling is achieved. Figure 7 shows the cooling performance curve of the OMM cooler.

Operational results confirm the cooler ability to increase the output power up to $14 \%$ at the design condition. Figure 8 shows the augmented power due to the operation of the cooling system in summer 2011. Power augmentation up to $14 \%$ has been recorded which is noteworthy in responding to the electricity demand in hot months. Moreover, a power augmentation of 1-2 MW is recorded in steam part of the combined cycle unit. Intense dryness of the plant area which is close to desert and also a well designed cooler are the main reasons for the considerable results.

4.2 Evaluation of humidity effect on the inlet air filters

Humidity and droplets can make the air filters wet and increase the differential pressure drop caused by them and consequently result in more power loss of the turbine, therefore it is important to study the effect of humidity generated by the cooling system on the operation of filters. As an experimental work, a test simulator (wind tunnel) is designed which consists of a centrifugal fan, media pad, water pump and distribution system, clean and dirty air filters and measurement instruments which simulates real conditions similar to evaporative cooler operation, Figure 9.

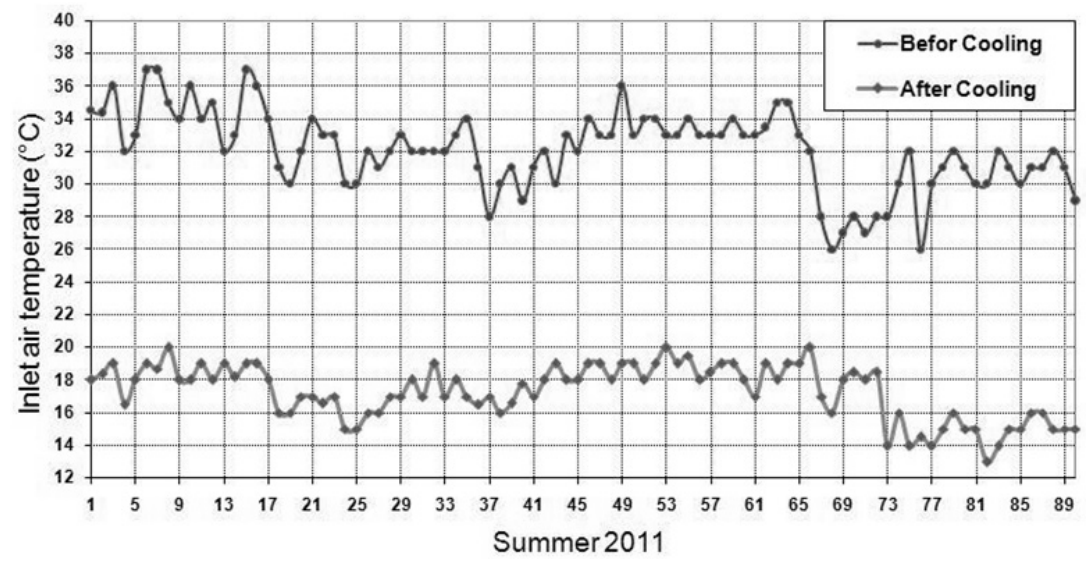

Figure 7. Cooling performance curve of the OMM cooler, summer 2011.

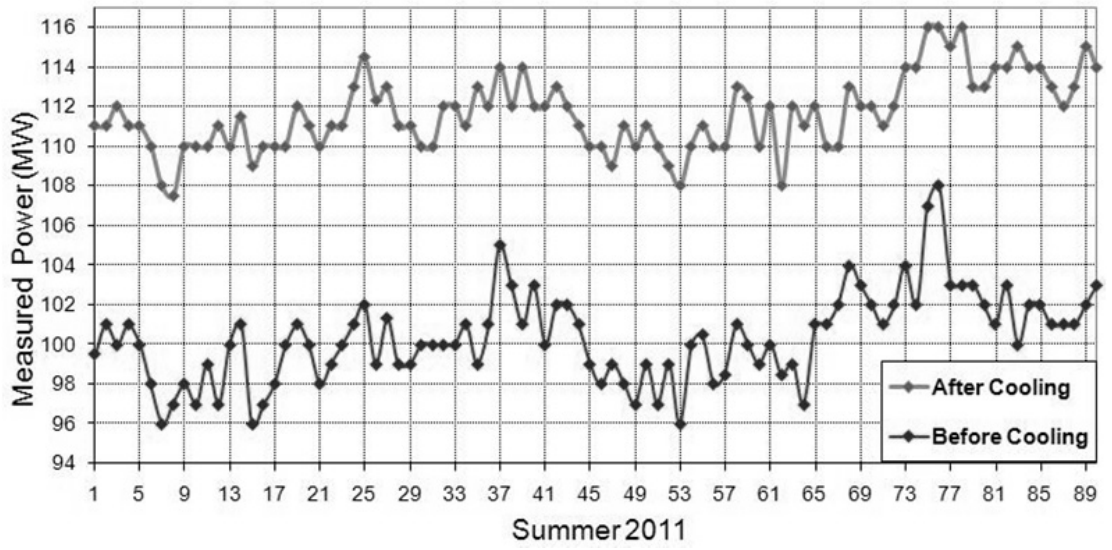

Figure 8. Curve of gas turbine output power, summer 2011. 
Three different test conditions were employed for each filter:

- Test no.1: 1 hour without evaporative cooling ( filter is dry)

- Test no.2: 9 hour during evaporative cooling (filter is wet)

- Test no.3: 5 hour after evaporative cooling (filter being dry)

Table 1 represents sample data resulted from testing a clean and a dirty filter.

Tests were performed for several days on three different dirty filters. Figure 10 shows the final result of the tests; a negligible increase of pressure drop was observed during the cooling system's operation, less than $25 \mathrm{~Pa}$, for both the clean and dirty filters. It can be concluded that the cooler would have no bad effect on the filters' operation and there is no need to substitute the existing filters with new ones, thus no extra cost is needed.

Real data extracted from the operation of the OMM cooling system confirms the results achieved by the laboratory tests. Figure 11 represents an average increase of about 20-30 Pa of a monthly operation of the cooling system which is negligible in comparison to several hundred Pascal pressure drop in regular operation of the filters.

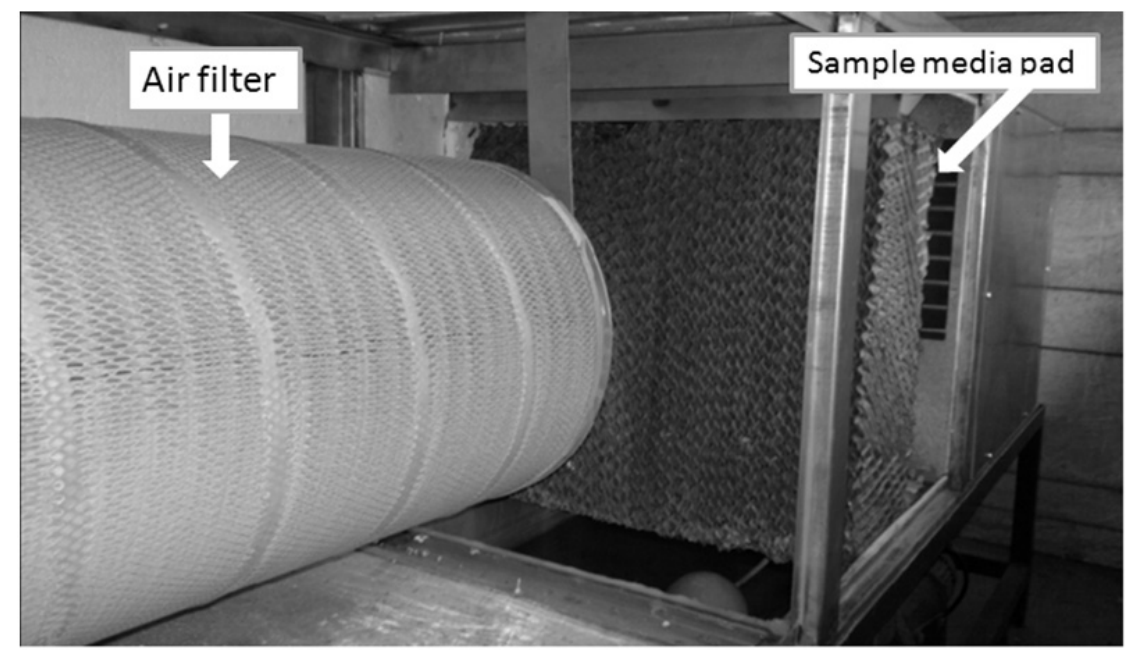

Figure 9. Inner view of the filter test simulator.

\begin{tabular}{lclll}
\hline & Test no. & $\mathrm{RH}(\%)$ & $\mathrm{T}\left({ }^{\circ} \mathrm{C}\right)$ & $\mathrm{DP}(\mathrm{Pa})$ \\
\hline \multirow{3}{*}{ Clean filter } & 1 & 16.85 & 36.76 & 385 \\
& 2 & 83.86 & 23.29 & 401 \\
& 3 & 18.01 & 36.54 & 387 \\
\hline \multirow{2}{*}{ Dirty filter } & 1 & 17.9 & 36.37 & 446 \\
& 2 & 84.95 & 24.11 & 460 \\
& 3 & 20.1 & 36.21 & 449 \\
\hline
\end{tabular}

Table 1. Sample test results of a clean and a dirty filter. 


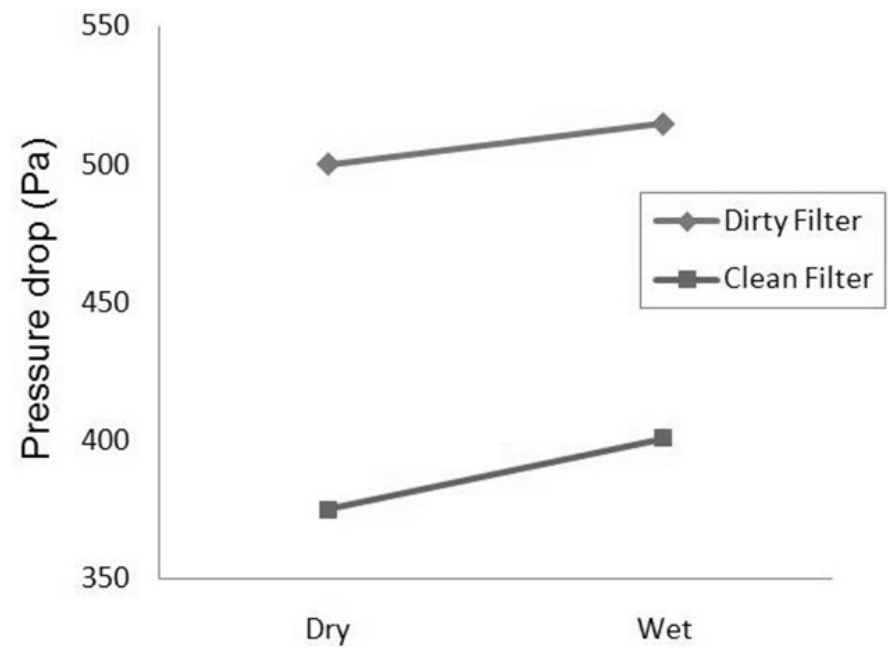

Figure 10. Change in pressure drop of the tested air filters due to humidity.

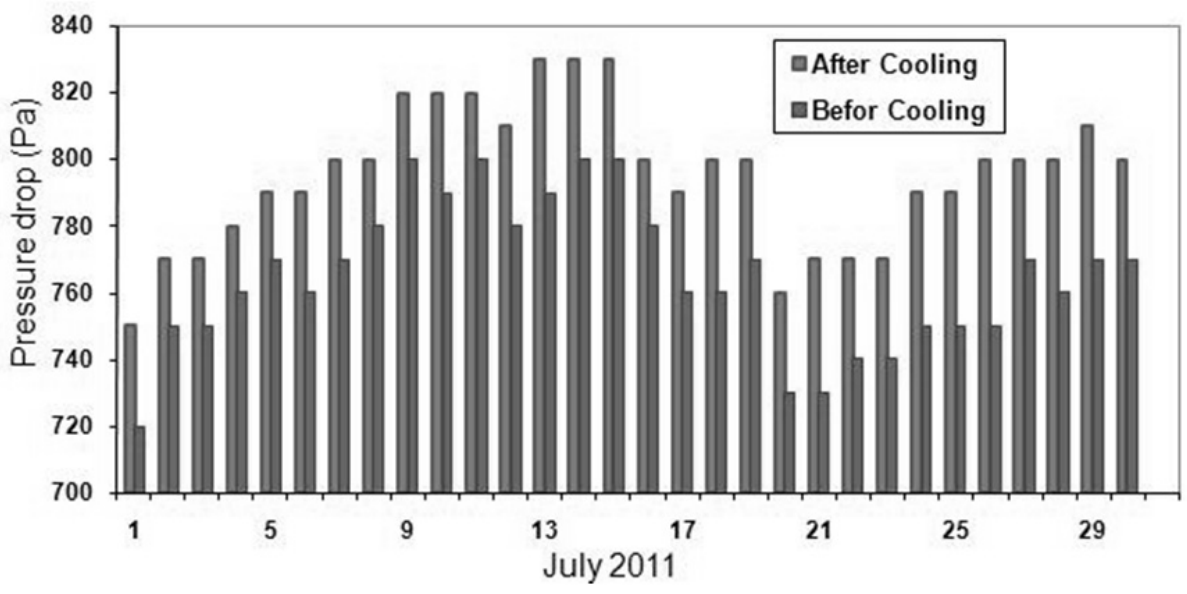

Figure 11. Recorded pressure drop of inlet air filters.

As stated in [11], media evaporative coolers were not tested for filtration efficiency, but it is known that they can act as an air washer system and remove substantial amounts of airborne particulates. To investigate the operation of the OMM cooler as a pre-filter, pressure drop curves of air filters of different turbines have been depicted in Figure 12. Turbines named GT13 \& GT14 were equipped with the OMM cooling system.

All the curves have an incremental ramp which is normal because of absorption of airborne particulates by filters, but it is obvious that the incremental ramp of the pressure drop curves related to turbines GT13 \& GT14 is less than the two others. Pressure drop increases of less than $100 \mathrm{~Pa}$ were observed for these two units, while an increase of 150 to $200 \mathrm{~Pa}$ has been recorded for units GT12 and GT16. These results confirm the upstream media evaporative cooler operation as a pre-filter of the inlet air, hence less pressure drop is imposed on the air filters and more power can be generated by the turbine. 


\section{Field Experiments and Technical Evaluation of an Optimized Media Evaporative Cooler for Gas Turbine Power Augmentation, A. Behdashti et al. / 458-471}

\subsection{Negligible Power Loss due to Inlet Pressure Drop}

As it was stated before, by installation of a movable media, the inlet pressure drop will be eliminated when the cooler is out of operation; subsequently, no output power loss occurs in this case. Operational results show a pressure drop of about $180 \mathrm{~Pa}(1.8 \mathrm{mbar})$ when the OMM cooler is not operating. As stated in [26], a correction factor must be applied to the gas turbine rated output power to take into account the effect of inlet pressure drop. From the correction curve which is shown in Figure 13, a correction factor of about 0.9973 must be applied to consider the pressure drop caused by the OMM cooler.
To compare the power loss caused by the installation of both the traditional media cooler and the optimized movable one, a calculation is done considering the following assumptions which are based on the Kerman C.C.P.P real data.

- The service period of the media cooler is between June 1st. and October 1 st..; i.e., 4 hot months of the year.

- As a mean value, the media cooler operates about 10 hours per day.

- In the service period, a mean value of about 98 $\mathrm{MW}$ is produced by the gas turbine in normal operation, while a mean value of $110 \mathrm{MW}$ can be reached when the media cooling system is operating. Also, in out-of-service period, which is about 8 months of year, the average output power is $115 \mathrm{MW}$.

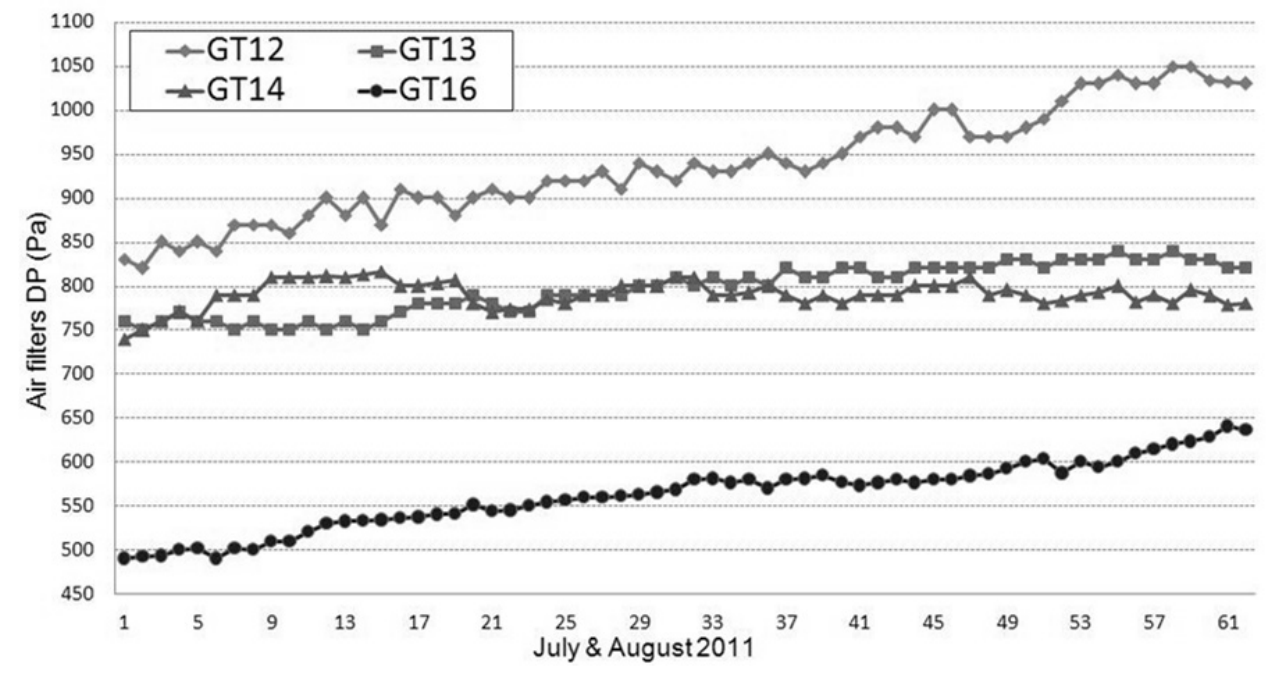

Figure 12. Recorded pressure drop of different turbines air filters. 


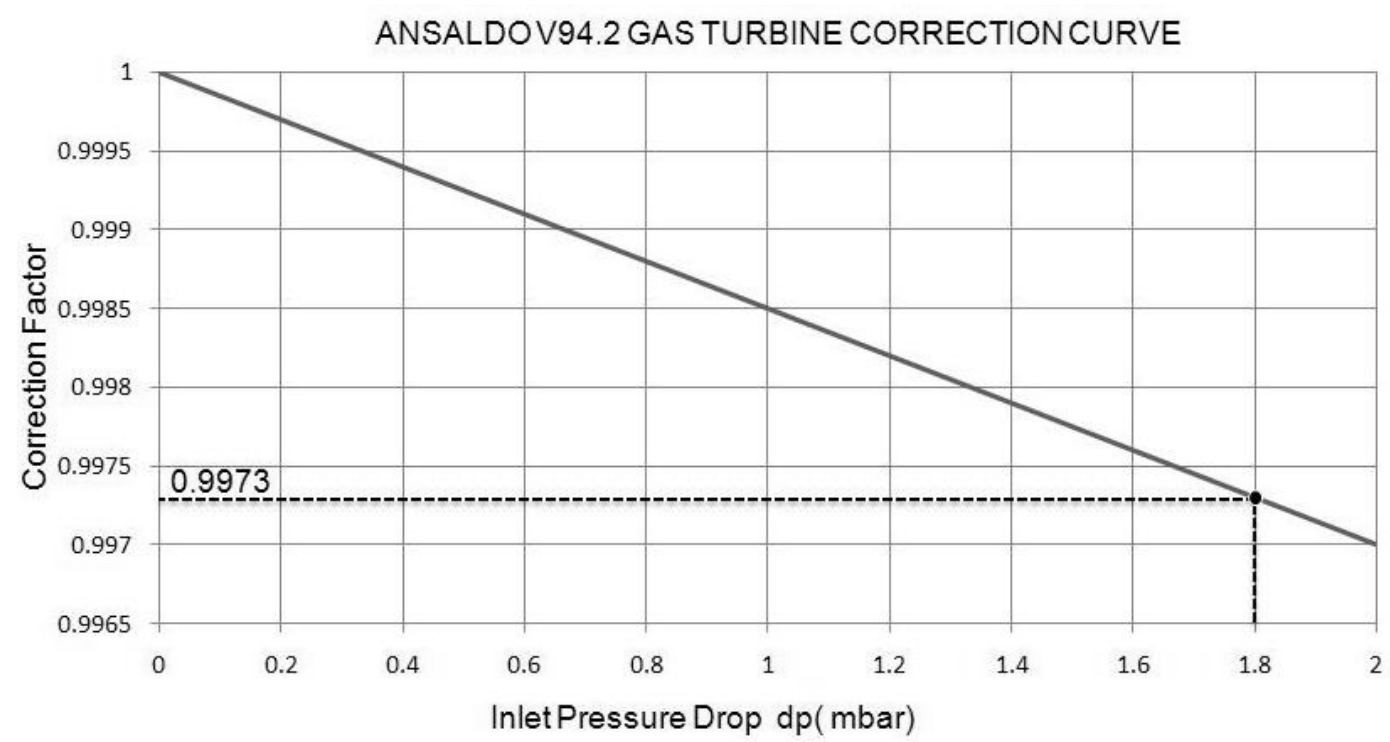

Figure 13. Effect of inlet pressure drop on output power.

Three scenarios have been considered as the next stage:

1. A traditional media cooler with media pads not removed during out-of-service period. This is a common case because of several issues such as difficulties related to removing and storing the pads which may result in damages to the brittle pads. These damages not only increase the water carryover phenomenon but also impose a cost to replace the damaged pads with new ones.

2. A traditional media cooler with removing pads in non-service period. As mentioned before, this case is rare.

3. The movable media cooler is installed and the pads impose a pressure drop only when the cooler is operating; i.e., 10 hours/day of the service period.

The turbine output power loss per year due to inlet pressure drop caused by the three different scenarios was calculated and shown in Figure 14. It can be concluded that scenario number 1 is the worst case in which the traditional media cooler caused a huge power loss per year, while the movable media cooler resulted in a power loss of only $356,400 \mathrm{kWh} /$ year which is negligible in comparison to $14,400,000 \mathrm{kWh} /$ year augmented power. This is the key advantage of the OMM cooler; only $2.5 \%$ of the augmented power will be lost during the year comparing to the common case of traditional media cooler in which approximately $18 \%$ will be lost.

\subsection{Reduced Fuel Consumption per Augmented Output Power}

All inlet air cooling systems improve the gas turbine's heat rate. This will reduce fuel consumption per augmented MW. A numerical study on the fuel consumption reduction by a fog cooling system was done by A.Behdashti [27]. Fuel factor is defined as the fuel consumption of the gas turbine per MW which is given by Equation 2:

$$
k_{f}=\frac{\dot{m_{\text {fuel }}}}{\dot{\mathcal{W}}_{\text {net }}}
$$




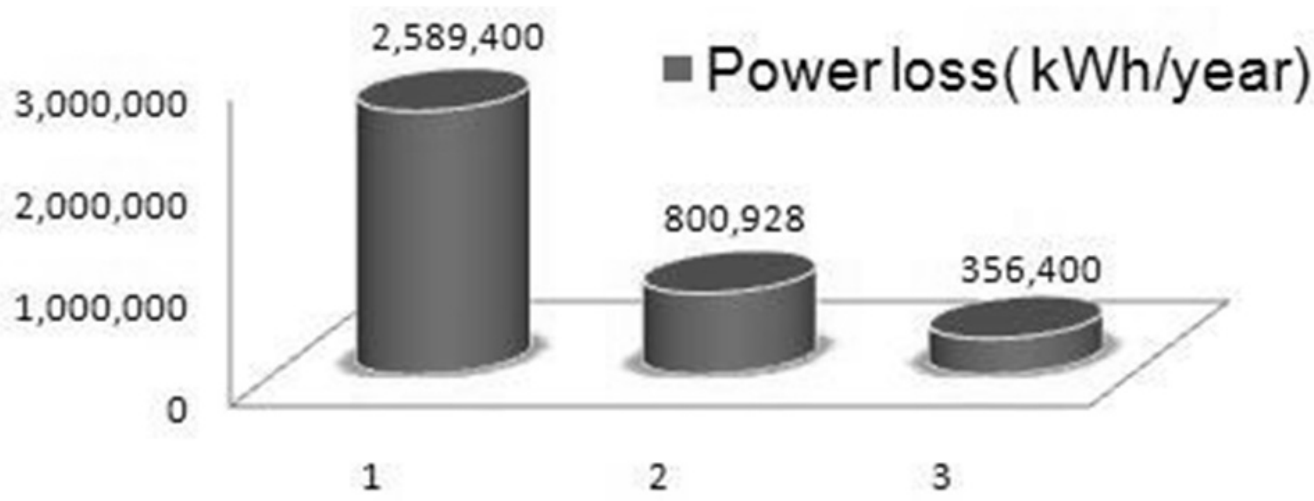

Figure 14. Power loss values in three different scenarios.

In which $\dot{m}_{f u e l}$ is the fuel mass flow rate in $\mathrm{kg} / \mathrm{s}$ and •

$w_{\text {net }}$ is the output power of gas turbine in MW. Using the outdoor movable media cooler will result in the inlet air temperature decrease and subsequently an increase in the fuel mass flow rate, hence another factor named cooling fuel factor is defined as the extra fuel per additional MW achieved by the media cooler. Considering simplifications such as a constant value for the efficiency and other related parameters, the cooling fuel factor can be calculated as follows:

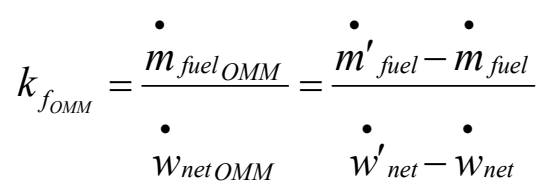

To determine the two fuel factors, a test was performed on the gas turbine unit 4 of Kerman C.C.P.P with natural gas fuel and base load. Test results are given in Table 2 .

Average values of 0.069 and 0.047 are calculated for $k_{f}$ and $k_{f_{O M M}}$, respectively; i.e., $k_{f_{\text {OMM }}}=0.68 k_{f}$. It means that each additional MW produced by the media cooler needs $30 \%$ less fuel in comparison to normal generation of the gas turbine without inlet cooling which is viable as an economical point of view.

Furthermore, the cooling system can improve the thermal efficiency of the gas turbine. From the test results shown in Table 2, the thermal efficiency is

\begin{tabular}{|c|c|c|c|c|c|}
\hline Test & Turbine status & $\mathrm{T}\left({ }^{\circ} \mathrm{c}\right)$ & $\mathrm{P}(\mathrm{MW})$ & Fuel $(\mathrm{kg} / \mathrm{s})$ & $\eta_{\text {th }}$ \\
\hline \multirow{2}{*}{1} & normal & 32 & 100 & 6.97 & $29.37 \%$ \\
\cline { 2 - 6 } & With inlet cooling & 14 & 114 & 7.57 & $30.83 \%$ \\
\hline \multirow{2}{*}{2} & normal & 31 & 101 & 7.01 & $29.50 \%$ \\
\cline { 2 - 6 } & With inlet cooling & 15 & 114 & 7.61 & $30.67 \%$ \\
\hline
\end{tabular}

Table 2. Test results of fuel consumption. 
increased about $1-1.5 \%$ which is viable. LHV of the natural gas used by power plant is about 21000 $\mathrm{Btu} / \mathrm{lb}$ which is considered in the calculation.

\section{Cost analysis}

The payback period of the cooling system for each gas unit can be calculated by considering several parameters as the following:

- A: The investment cost of installation of the movable media cooling system for each gas unit is about $\$ 600,000$.

- M: According to Section 3.3, the electricity generated as a result of the installation of the cooling system is about $14,400,000 \mathrm{kWh} /$ year, from which an amount of about 356,400 $\mathrm{kWh} /$ year, due to power loss during the operation of the system, must be subtracted. The current cost of electricity in Iran is 2.5 Cents/kWh; therefore, the income of electricity generated due to the cooling system operation is about $\$ 351,000 /$ year.

- B: The cooling system uses about $1 \mathrm{~m}^{3}$ soft water for each MWh increase in electricity generation, while the cost of each $\mathrm{m}^{3}$ soft water is currently about $\$ 5$. Thus, an amount of $\$ 72,000 /$ year should be considered totally.

- C: Due to ECA, Energy Conversion Agreement, the power plant does not charge for the fuel; hence, it can be withdrawn from the calculation of the payback period.

- D: The operation and maintenance cost of the cooling system is about $3 \%$ of the investment cost per each year.

- E: The electricity consumption of the cooling system is about $15 \mathrm{kWh}$; therefore, a cost of about $\$ 450 /$ year should be considered.

Now the simplified payback period can be calculated by Equation 4:

$$
\begin{gathered}
Y=\frac{A}{M-(B+C+D+E)} \\
Y=\frac{600,000}{351,000-(72,000+0+18000+450)} \approx 2.3 \text { year }
\end{gathered}
$$

It should be noted that by considering other parameters such as inflation, the payback period would not be more than 3 years.

\section{Conclusion}

An optimized media evaporative cooler has been described in this paper. Optimizations such as making a movable media cooler, a well designed outdoor cooler box to ensure the suitable air velocity on media pads and a local water treatment unit to decrease the blow down rate and to ensure water quality, have been implemented to overcome existing problems related to conventional media coolers.

Results of an experimental work and real collected data show that the humidity generated by the cooler does not have any bad effect on the air filters and the upstream installation of the cooler helps the filtration process; hence, the filters recorded pressure drop is less than others.

Additionally, the system performance during a fourmonth operation of the first service period has confirmed the effectiveness of these optimizations. Turbine output power augmented up to $14 \%$, more than the $15 \%$ decrease in power loss (annually) compared to traditional media coolers because of using a movable cooler, $30 \%$ reduction in fuel consumption per each augmented $\mathrm{MW}$ and approximately $25 \%$ less water consumption are the main advantages, gained by the OMM cooling system. The simplified payback period of the cooling system is calculated which is not more than 3 years considering other parameters such as inflation.

\section{Nomenclature}

$T_{D B}$ dry bulb temperature of inlet air

$T_{W B}$ wet bulb temperature of inlet air

$T_{\text {actual inlet cooled air temperature }}$

$\bullet$

$m_{\text {fuel }_{\text {омм }} \text { augmented fuel mass flow rate in } \mathrm{kg} / \mathrm{s} \text { due to }}$ OMM cooler operation 


$$
\text { • }
$$

$\mathcal{W}_{\text {net }}$ OMM augmented output of gas turbine in MW due to OMM cooler operation

$$
\begin{aligned}
& \dot{m}^{\prime} \text { fuel fuel mass flow rate in } \mathrm{kg} / \mathrm{s} \text { after OMM cooler } \\
& \text { operation }
\end{aligned}
$$

$$
\begin{aligned}
& \dot{w}^{\prime} \text { net output power of gas turbine in MW after OMM } \\
& \text { cooler operation }
\end{aligned}
$$

$\eta_{t h} \quad$ thermal efficiency of gas turbine

$L H V$ Lower heating value in Btu/lb

\section{References}

[1] El-Hadik, The impact of atmospheric conditions on gas turbine performance, ASME J. Eng. Gas Turbine \& Power, vol.112, no. 4, pp. 590-596, 1993.

[2] Thamir K. Ibrahim, M. M. Rahman and Ahmed N., Improvement of gas turbine performance based on inlet air cooling systems: A technical review, International Journal of Physical Sciences, Vol. 6, no. 4, pp. 620-627, 2011.

[3] Meher-Homji, C.B., Mee, T. R., Inlet Fogging of Gas Turbine Engines, Part A: Theory, Psychometrics and Fog Generation, Proceedings of ASME Turbo Expo, Munich, 2000.

[4] Gareta, R., Romeo, L. M., Gil, A., Methodology for the economic evaluation of gas turbine air-cooling systems in combined cycle applications, J. Energy, V29, pp. 18051818, 2004.

[5] Omidvar, B., Gas Turbine Inlet Air Cooling System, The 3rd Annual Australian Gas Turbine Conference, Melbourne, Australia, 2001.

[6] Jolly, S., Sheperd, DW., Nitzken, JA., Cummings, RB., Linkous, Jr. FJ., Inlet air cooling for a frame 7EA based combined cycle power plant, Power-Gen International, pp. 1-12, 1997.
[7] Sanaye, S., Fardad, A., Mostakhdemi, M., Thermoeconomic optimization of an ice thermal storage syatem for gas turbine inlet cooling , Energy, vol. 36, pp.1057-1067, 2011.

[8] Ameri, M., Hejazi, SH., Montaser, K., Performance and economic of the thermal energy storage systems to enhance the peaking capacity of the gas turbines, Appl. Ther. Eng., Vol.25, pp. 241-251, 2005.

[9] De Lucia, M., Lanfranchi, C., Boggio, V., Benefits of compressor inlet air cooling for gas turbine cogeneration plants, Proceedings of the International Gas Turbine and Aero-engine Congress and Exposition, Houston Texas, pp. 5-8, 1995.

[10] Farzaneh-Gord, M., Deymi-Dashtebayaz, M., Effect of various inlet air cooling methods on gas turbine performance energy, Energy, vol. 36 , pp. 1196-1205, 2011.

[11] Johnson, R.S., The theory and operation of evaporative cooler for industrial gas turbine, J. Eng. Gas Turbine \& Power, vol. 111, pp. 327-334, 1989.

[12] Hosseini, R., Beshkani, A., Soltani, M., Performance improvement of gas turbines of Fars (Iran) combined cycle power plant by intake air cooling using a media evaporative cooler, Ener. Conver. Manage., vol. 48, pp.1055-1064, 2007.

[13] Beshkani, A., Hosseini, R., Numerical modeling of rigid media evaporative cooler, Appl. Ther. Eng, vol. 26, no.6, pp. 636-643, 2006.

[14] Johnson, RS. , Set up and operation of a recirculating wetted rigid media evaporative cooler installed in a gas turbine combustion inlet air system, International gas turbine and aero engine congress and exposition, The Hague, Netherlands, 1994.

[15] Chaker, M., Meher-Homji, C. B., and Mee, T. R.,Inlet Fogging of Gas Turbine Engines-Part A: Fog Droplet Thermodynamics, Heat Transfer and Practical Considerations, ASME Paper No.2002-GT-30562.

[16] Chaker, M., Meher-Homji, C. B., and Mee, T. R., Inlet Fogging of Gas Turbine Engines-Part B: Fog Droplet Sizing Analysis, Nozzle Types, Measurement and Testing, ASME Paper No. 2002-GT-30563.

[17] Sanaye, S., Tahani, M., Analysis of gas turbine operating parameters with inlet fogging and wet compression processes, Applied Thermal Engineering, vol. 30, pp. 234-244, 2010. 
[18] Chaker, M., Meher-Homji, C. B., Gas Turbine Power Augmentation: Parametric Study Relating to Fog Droplet Size and Its Influence on Evaporative Efficiency, J. Eng. Gas Turbines Power, vol. 133, 2011.

[19] Farzaneh-Gord, M., Deymi-Dashtebayaz, M., A New Approach for Enhancing Performance of a Gas Turbine (case study: Khangiran Refinery), Applied Energy, vol. 86, pp. 2750-2759, 2009.

[20] Farzaneh-Gord, M., Deymi-Dashtebayaz, M., Hashemi-Marghzar, Sh., Improving Efficiency of an Industrial Gas Turbine by a Novel Inlet Air Cooling Method, Journal of the Energy Institute, vol. 82, no.3, 2009.

[21] MEE INDUSTRIES INC, Economic Benefits of Replacing Gas Turbine Media Based Evaporative Cooling with Inlet Fogging Systems, AN-GT-205, Rev: 1, 2002.

[22] Zadpoor, A.A., Golshan, A.H., Performance improvement of a gas turbine cycle by using a desiccantbased evaporative cooling system, J. Energy., vol. 31, pp. 2652-2664, 2006.

[23] Kraneis, W., The increased importance of evaporative coolers for gas turbine and combined-cycle power plants, VGB PowerTech, Munters Corp, 2000.

[24] Technical specification of the project, Design, manufacturing and installation of media evaporative cooling system for 2 units of Kerman combined cycle power plant, Kerman Power Generation Company, 2010.

[25] Cooling media pads catalogue, Munters corp., Available online: http://www.munters.com/upload/Relatedproductfiles/Celd ek7090-English.pdf

[26] ANSALDO Energia, V94.2 Gas turbine operation and maintenance manual, 30 GT Project in Iran, Vol.1, 2000.

[27] Behdashti, A., Mohammadi, E., Mohammadi, A., Reduction of Gas turbines fuel consumption by means of Fog cooling system, 6th National Energy Congress, Iran, 2007. 